\title{
DIAGNOSTYKA OBIEKTÓW Z WYKORZYSTANIEM KAMERY TERMOWIZYJNEJ
}

\begin{abstract}
Termowizja to dziedzina techniki, zajmująca się detekcją, rejestracją i zobrazowaniem promieniowania podczerwonego, emitowanego z powierzchni badanego obiektu. W efekcie powstaje termogram, pokazujący rozkład temperatury na powierzchni obserwowanego obiektu. Ta technika pomiarowa stosowana jest między innymi w medycynie, podczas realizacji prac badawczych i rozwojowych, w niektórych gałęziach przemysłu, transporcie, ratownictwie oraz w wojskowości. Jest to także metoda szybkiej, w miarę dokładnej i, co ważne, nieinwazyjnej oceny cech termicznych budynku. Pozwala np. na lokalizację mostków cieplnych, nieciągłości izolacji, zawilgocenia przegród, nadmiernej infiltracji powietrza czy wreszcie wyznaczanie przebiegu instalacji grzejnych i elektrycznych. Należy pamiętać, że badania termowizyjne są bardzo ważnym składnikiem szerszego procesu jakim jest diagnostyka obiektów budowlanych. Celem tej pracy jest przedstawienie wybranych informacji nt. zastosowania pomiarów termowizyjnych w ocenie budynków. Wskazano na powszechnie popełniane błędy przy wykonywaniu termogramów, a w szczególności na wyznaczanie właściwego współczynnika emisyjności badanej powierzchni. Wspomniano również o innych uchybieniach w pomiarach, mających wpływ na osiągnięte wyniki np. nieostrość obrazu, niezachowanie kilkunastostopniowej różnicy temperatur na zewnątrz i wewnątrz budynku czy zignorowanie nasłonecznienia w dniu pomiaru (im mniejsze tym pomiar dokładniejszy). W części praktycznej tej pracy zawarto kilka przykładów zastosowania termowizji do wyznaczenia mostków w wykonanej izolacji termicznej ścian zewnętrznych, poszukiwania instalacji umieszczonej pod tynkiem czy stwierdzania nadmiernej infiltracji powietrza przez drzwi. Całość zilustrowano termogramami, wykonanymi w większości przez autora tej publikacji przy zastosowaniu kamery termowizyjnej Fluke TiR32.
\end{abstract}

Słowa kluczowe: podczerwień, termogram, mostki termiczne, emisyjność powierzchni

\footnotetext{
${ }^{1}$ Dr hab. inż. Norbert Szmolke, prof. PO, Politechnika Opolska, Katedra Inżynierii Środowiska, ul. S. Mikołajczyka 5, 45 - 271 Opole, Tel. 7744983 91, e-mail: n.szmolke@ po.opole.pl
} 


\section{Wprowadzenie}

Pod pojęciem termowizji kryje się, wykorzystywana od lat 60-tych ubiegłego wieku, technika pomiarowa, polegająca na rejestracji obrazu, emitowanego w podczerwieni przez badany obiekt. Stosowana jest powszechnie w wielu dziedzinach nauki i techniki, m.in.:

- wspomagania przemysłu (kontrola linii produkcyjnych, wykrywanie i lokalizacja defektów w obiektach budowlanych, monitorowanie linii przesyłowych energii elektrycznych, diagnostyka maszyn i urządzeń, kontrola dystrybucji ciepła),

- $\mathrm{w}$ medycynie (diagnostyka medyczna, wspomaganie operacji czy badania skuteczności leków); tutaj wykorzystuje się ważną cechę organizmu ludzkiego jaką jest to, że rozkład temperatury na powierzchni ciała ludzkiego zależy m.in. od temperatury narządów wewnętrznych,

- badań i rozwoju (obserwacje meteorologiczne, obserwacja wulkanów i innych fragmentów powierzchni Ziemi, analiza strat ciepła i mechanizmów przewodzenia ciepła, projektowanie silników),

- w wojskowości (wykrywanie celów, systemy śledzenia obiektów i naprowadzania na nie, broń ,inteligentna”),

- w ratownictwie (lokalizacja ofiar, lokalizacja ognia, obserwacja zjawisk w przestrzeniach zadymionych),

- w transporcie (monitorowanie ruchu pojazdów samochodowych i lotniczych),

- w ochronie (ochrona granic, wykrywanie intruzów, systemy alarmowe) [2].

Celem tej pracy jest przedstawienie wybranych informacji nt. zastosowania pomiarów termowizyjnych $\mathrm{w}$ diagnostyce obiektów budowlanych. Zostaną omówione popełniane błędy przy wykonywaniu termogramów. W części praktycznej zawarto kilka przykładów zastosowania termowizji do wyznaczenia mostków w wykonanej izolacji termicznej ścian zewnętrznych, poszukiwania instalacji umieszczonej pod tynkiem czy stwierdzania nadmiernej infiltracji powietrza przez drzwi. Całość zilustrowano termogramami, wykonanymi przez autora tej publikacji przy zastosowaniu kamery termowizyjnej Fluke TiR32 [1].

\section{Termowizja w budownictwie}

Głównym zadaniem badań termowizyjnych, wykonywanych na obiektach budowlanych, jest kontrola jakości izolacji termicznej i lokalizacja mostków termicznych. Pozwalają one na szybką, nieinwazyjną diagnostykę wykonanych prac termoizolacyjnych, a szczególnie jakości ich wykonania. Należy pamiętać, że ze względu na szereg trudności w przeprowadzeniu badań na tego typu obiektach ich wyniki często mają charakter jakościowy. Możliwe jest wskazanie miejsc o innej temperaturze niż temperatura otoczenia bez wyznaczania jej 
konkretnej wartości. Ponadto należy zauważyć, że badania termowizyjne są bardzo ważnym składnikiem szerszego procesu jakim jest kompleksowa diagnostyka obiektów budowlanych.

Podstawowym problemem, który pojawia się podczas pomiarów termowizyjnych jest wyznaczenie współczynnika emisyjności $\varepsilon$ powierzchni emitującej promieniowanie podczerwone. Jego błędne wyznaczenie może prowadzić do uzyskania wyników, znacznie odbiegających od wartości rzeczywistej (rys.1). Im niższa jest wartość tego parametru tym wyznaczona, na podstawie termogramu, temperatura jest wyższa. Istotna rolę odgrywa także temperatura odniesienia.

Badania termowizyjne w budownictwie wykorzystywane są do sprawdzania jakości i szczelności izolacji budynków. Są szybką, nowoczesną i niezawodną metodą diagnostyczną izolacyjności cieplnej budynków oraz jakości wykonania izolacji. Na wiarygodność pomiaru temperatury przy pomocy termowizji ma wpływ szereg czynników towarzyszących pomiarowi. Dokładny pomiar rozkładu temperatury wymaga dodatkowych zabiegów mających na celu określenie emisyjności badanej powierzchni, wyeliminowanie wpływu ewentualnych błędów w jej wyznaczeniu oraz określenie wpływu otoczenia na wynik pomiaru. $\mathrm{Z}$ powodu tych trudności $\mathrm{w}$ termowizyjnych badaniach izolacyjności cieplnej ścian budynków stosuje się na ogół podejście jakościowe, lokalizując jedynie miejsca o podwyższonej temperaturze i tym samym o nadmiernych stratach ciepła, nie dążąc się do wyznaczenia dokładnej wartości temperatury.
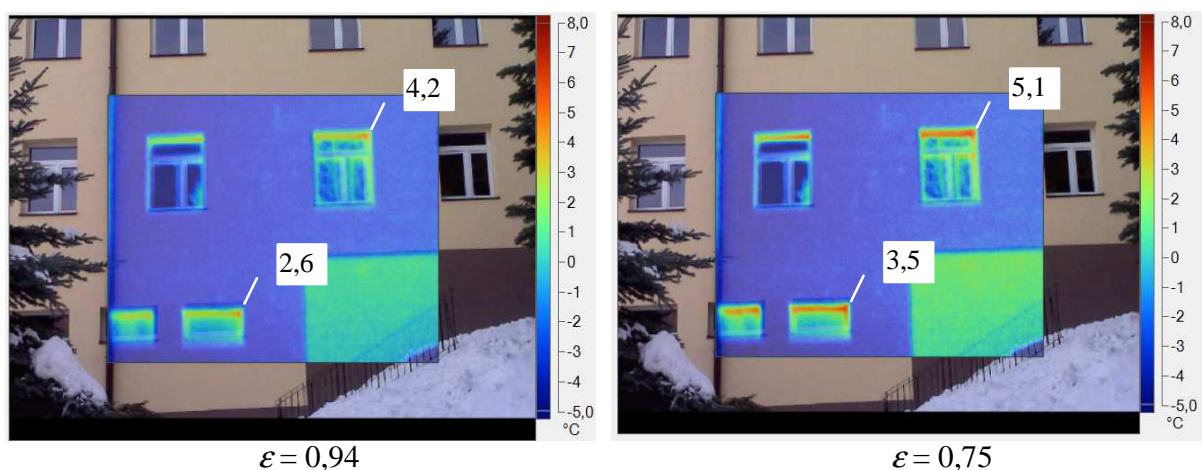

Rys.1. Przykład wpływu współczynnika emisyjności $\varepsilon$ na wyniki pomiarów temperatury

Fig.1. Example of the effect of heat emissivity coefficient $\varepsilon$ on the results of temperature measurements

Dodatkowo, aby badanie było wiarygodne i doszło do skutku, różnica temperatur na zewnątrz i wewnątrz budynku powinna wynosić przynajmniej $15^{\circ} \mathrm{C}$. Istotnym czynnikiem jest również nasłonecznienie (im mniejsze tym lepiej).

W budownictwie badania termowizyjne stosowane są również w celu określenia np. czy ramy stolarki okiennej są osadzone poprawnie, do wykrywania wad ogrzewania podłogowego oraz niedrożności instalacji grzewczej. 
W ostatnich latach pomiary termowizyjne służą producentom okien, wykonywanych z PVC i nie tylko, do oceny jakości tzw. „,ciepłej ramki” co staje się niestety elementem ich walki o utrzymanie pozycji na rynku wytwórców.

Wspomnieć należy także, że okres wykonywania badań z użyciem kamery termowizyjnej ograniczony jest w zasadzie do tzw. sezonu grzewczego, co spowodowane jest koniecznością uzyskania odpowiedniej różnicy temperatur po obu stronach przegrody.

\section{Przykłady badań z zastosowaniem kamery termowizyjnej}

W tej części pracy pokazano przykłady termogramów, powstałych podczas diagnostyki obiektów budowlanych, zlokalizowanych w Polsce południowozachodniej.

Jako pierwszy (rys.2a) pokazano termogram pozwalający na lokalizację pionu grzejnego ulokowanego w bruździe ściennej. Kolejny rysunek (rys.2b) przedstawia ułożenie kanału spalinowego, zlokalizowanego w ścianie zewnętrznej.

Na rys. 3a pokazano liczne mostki cieplne, które powstały w wyniku niestarannego ułożenia ocieplenia ze styropianu. Widoczne są krawędzie płyt co oznacza, że podczas ich przyklejania nie przylegały do siebie a powstałe $\mathrm{w}$ ten sposób szczeliny wypełniono masą klejową.

Na rys. 3 b pokazano mostek termiczny, powstały w skutek niedbałego ułożenia izolacji termicznej w okolicy narożnika wnęki okiennej. Zapewne spowodowany jest złym docięciem płyty izolacyjnej i słabym wypełnieniem powstałej w ten sposób szczeliny.
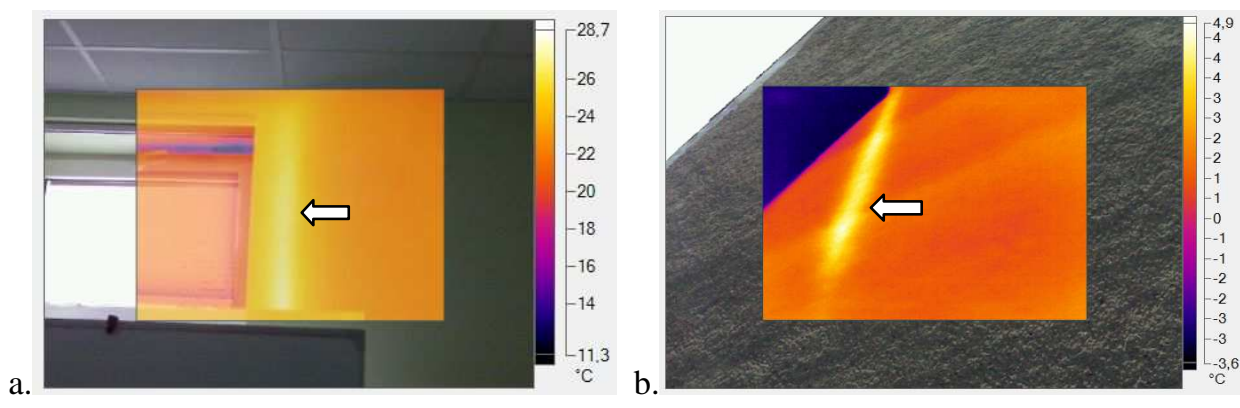

Rys.2. Lokalizacja instalacji w budynku

a. pion grzejny w ścianie

b. komin spalinowy

Fig.2.Location of building installations

a.riser heating in the wall

b.combustion stack. 

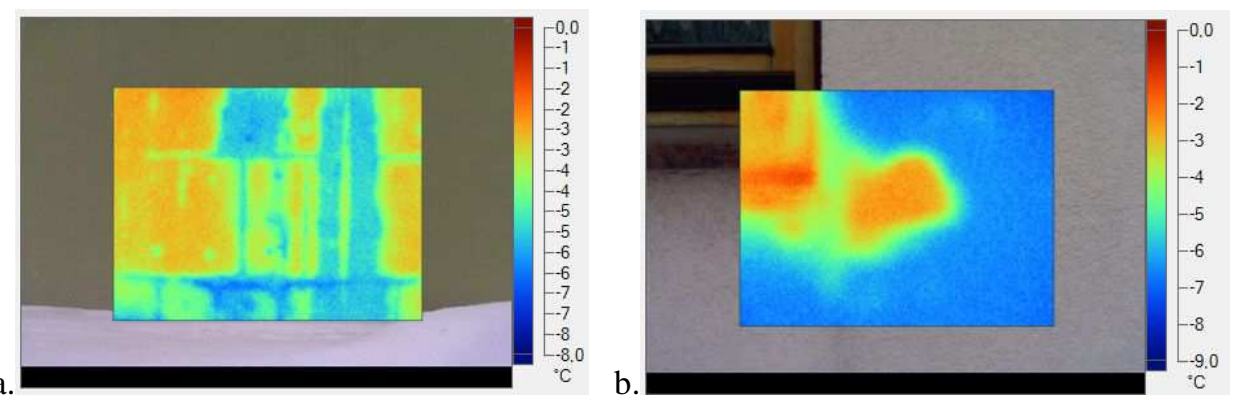

Rys.3. Diagnostyka ocieplenia - mostki termiczne

a. ściana zewnętrzna

b. narożnik wnęki okiennej

Fig.3. Diagnostics insulation - thermal bridges

a. of external wall

b. corner of window alcove

Następne termogramy, pokazane na rysunku 4, wskazują na infiltrację powietrza przez stolarkę drzwiową. Aby ocenić, czy jest ona właściwa i dopuszczalna należałoby odnieść wyniki pomiarów do warunków jej występowania w badanym obiekcie. Bez przeprowadzenia tych czynności wyciąganie jakichkolwiek wniosków będzie błędem.
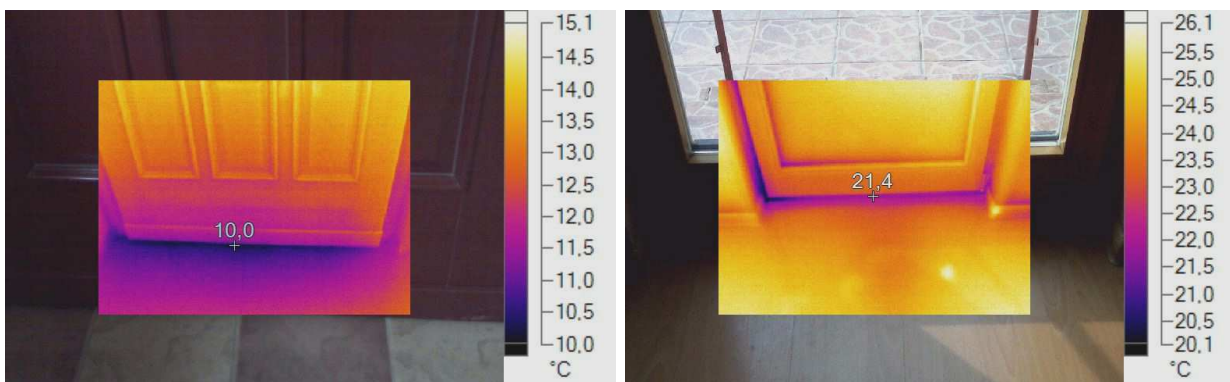

Rys.4. Infiltracja powietrza przez stolarkę drzwiową

Fig.4. Air infiltration through the door joinery

\section{Błędy popełniane podczas pomiarów termowizyjnych}

Do powszechnie popełnianych błędów podczas wykonywaniu badań za pomocą kamery termowizyjnej należy zaliczyć:

- niewłaściwe wyznaczenie bądź oszacowanie współczynnika emisyjności (p. rozdział 2),

- niewłaściwie określoną wielkość rejestrowanego obrazu, co powiązane jest ze zbyt dużą odległością kamery od badanego obiektu oraz jej ustawienia w stosunku do badanej powierzchni, 
- niewłaściwie ustawioną ostrość obrazu (rys.5a),

- wyeksponowanie nieboskłonu (rys.5b),
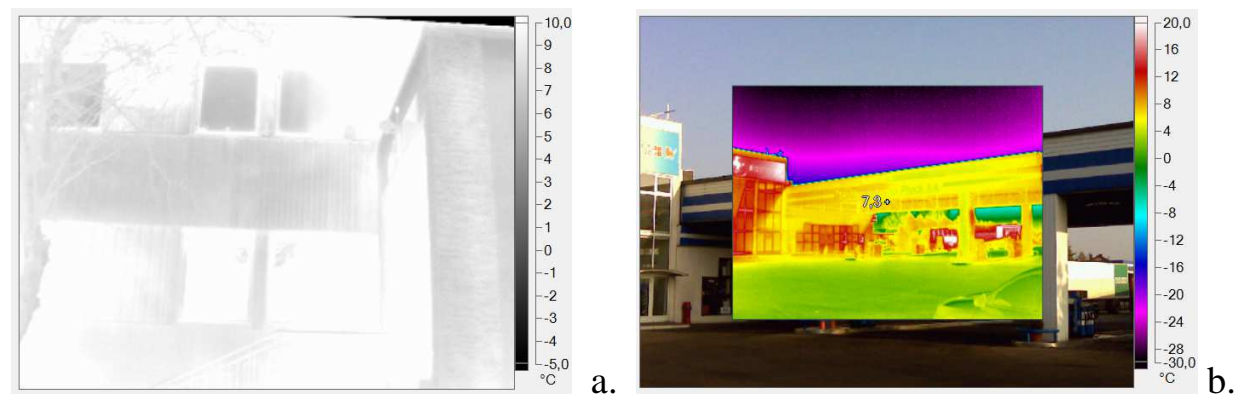

Rys.5. Błędy pomiarowe

a. obraz nieostry

b. wyeksponowanie nieboskłonu

Fig.5. Measurement errors

a. picture out of focus

b. visibility the firmament

- brak umiejętności operatora,

- zlekceważenie wpływu warunków atmosferycznych w jakich przeprowadzony jest pomiar,

- zbyt mała różnica temperatur pomiędzy wnętrzem budynku a jego otoczeniem,

- niepoprawna interpretacja termogramów,

- brak rozpoznania obiektu badań przed wykonaniem pomiarów,

- pominięcie takich istotnych elementów jak nadmiernie rozgrzane grzejniki centralnego ogrzewania, działające oświetlenie pomieszczeń, zły kąt ustawienia kamery w stosunku do badanej powierzchni .

Powyższe zestawienie nie wyczerpuje wszystkich możliwych błędów; jest ich znacznie więcej, a ich obszerne omówienie można znaleźć w pracy [3]. Tam też zwrócono uwagę, że aby uniknąć większości błędów należy mieć świadomość ograniczeń samej metody pomiarowej oraz należy konsekwentnie przestrzegać procedur i zasad wykonywania pomiarów.

Autor tej pracy zauważył także, w nawiązaniu do interpretacji termogramów, że nie każde zróżnicowanie rozkładu temperatur na granicznych powierzchniach przegród świadczy o usterkach w ich izolacji, nadmiernej infiltracji powietrza przez przegrody czy ich zawilgoceniu. Często pobieżna analiza obrazu z kamery termograficznej może doprowadzić do wyciągnięcia pochopnych wniosków. 


\title{
5. Podsumowanie
}

Pomiary z wykorzystaniem kamer termowizyjnych będą w najbliższej przyszłości wykonywane coraz częściej ze względu na ich prostotę, szybkość realizacji i przydatność. Osiągane wyniki wydają się być coraz dokładniejsze, szczególnie jeśli oczekuje się jakościowego podejścia do rezultatów. Jednakże, jak wynika również z doświadczeń autora tej pracy, ilościowa informacja o temperaturze na powierzchni przegrody jest bezwartościowa jeśli nie zostaną podane (i uwzględnione w analizie) informacje o warunkach wykonania pomiarów. Sam termogram podaje informacje o rozkładzie temperatury w wybranym obszarze pomiarowym, które mogą być istotne, pod warunkiem odniesienia ich do charakterystyki analizowanego obiektu i, idących za tym, informacji o mechanizmach przepływu ciepła w nim występujących.

Celem tej pracy było przedstawienie wybranych informacji nt. zastosowania pomiarów termowizyjnych w diagnostyce budynków. Wskazano na powszechnie popełniane błędy przy wykonywaniu termogramów, w tym trudności w wyznaczaniu współczynnika emisyjności przegrody. Całość zilustrowano termogramami, obrazującymi występowanie mostków termicznych czy nieciągłości w wykonanej izolacji cieplnej.

\section{Literatura}

[1] Fluke: Test tools catalog 2013-14, Wydawca Fluke Europe BV, Eindhoven, Holandia 2013.

[2] Madura H., Minkinia W.: Budowa, parametry i zastosowania kamer termowizyjnych. Pomiary termowizyjne w praktyce. Wydawnictwo Agencja Wydawnictwa PAK, 2004.

[3] Nowak H.: Zastosowanie badań termowizyjnych w budownictwie. Wydawnictwo Oficyna Wydawnicza Politechniki Wrocławskiej, Wrocław 2012.

\section{DIAGNOSTICS OF BUILDINGS USING THERMAL IMAGING TECHNIQUES}

\author{
S u m m a r y \\ Thermal imaging is a field of engineering which deals with detecting, recording and imaging of \\ ultra-violet radiation emitted from the surface of the examined object. As a result, a thermogram \\ can be formed to illustrate the distribution of temperatures along the surface of the observed ob- \\ ject. This method enables a quick, precise and non-invasive assessment of thermal parameters of \\ a building. This also makes it possible to locate thermal bridges, non-continuous elements in insu- \\ lation, moisture in the internal barriers, excessive air infiltration and the course of the thermal and \\ electrical installations. This paper deals with selected information regarding the application of \\ thermal visual measurement in the assessment of buildings. The common errors during the prepa- \\ ration of thermograms are presented. Other subjects dealt with cover other types of errors made in
}


measurements which affect their results, such as: blurred image quality, lack of specific range of temperature intervals between the exterior and interior of a building or the fact of ignoring the influence of sun on the days of the measurement (the smaller the sun exposition, the more precise measurement can be made). The practical part of the paper includes a few examples of applying thermal imaging for determining thermal bridges in the thermal insulation installed on the external walls, search for wall installation or indication of excessive air infiltration through the doors The paper is complemented with thermograms which were predominantly prepared by the author of this paper with the use of Fluke TiR32 camera for thermal imaging.

Keywords: infrared, thermogram, thermal bridges, the emissivity of the surface

Przestano do redakcji: $22.02 .2015 \mathrm{r}$.

Przyjęto do druku: 22.06.2015 r.

DOI:10.7862/rb.2015.76 